\title{
DECOMPOSITION OF GDP GROWTH RATES IN 2016-2019: IN EXPECTATION OF STRUCTURAL CHANGES ${ }^{1}$
}

\author{
S.Drobyshevsky, M.Kazakova
}

Calculations of decomposition of the RF GDP growth rates in 1999-2015 and the MED's forecast for 2016-2019 show that in current conditions cyclical components related to the domestic business cycle's entering the positive phase are the only source of economic growth. However, they alone are insufficient to ensure growth rates of $4 \%$ or more. To achieve that, it is important to increase structural economic growth rates, too. In particular, with the aggregate factor productivity to be retained at the present level it is necessary to attract to the economy further labor resources of about $4.5 \mathrm{~m}$ people and $R b$ 40 trillion worth of additional investments in capital assets in 2016-2018.

In mid-May 2016, a working group - in the line: Priorities of Structural Reforms and Stable Economic Growth - of the Economic Council under the RF President was established. The above group is led by Alexei Kudrin, Chairman of the Center for Strategic Research. According to the order of the RF President, the working group will deal with "identification of actual problems preventing stable economic growth and progress in structural reforms and development of proposals on resolution thereof"2. Incidentally, amid protracted stagnation of the Russian economy and forthcoming elections in 2016 and 2018 debates on the factors of sustained long-term economic growth renewed. In particular, development of measures required to be taken to ensure GDP growth of $4 \%$ by 2019 is currently on agenda (see for example: http://www.interfax.ru/business/509695).

Early in May, the RF Ministry of Economic Development (MED) issued an updated version of the forecast of Russia's socioeconomic development for the period of three years (until 2019). Traditionally, the forecast includes three scenarios: baseline, conservative and target ones. As stated in the MED's documents, "the forecast proceeds from the fact that development of the Russian economy takes place amid prevailing geopolitical instability, sanctions imposed against Russia over the entire forecast period by the EU and the US that limit considerably Russian companies' access to global capital markets and retaliatory economic measures" ${ }^{\prime 3}$.

The baseline forecast scenario envisages Russia's moderate economic development amid falling consumer demand due to restrained growth in the government's social obligations. So, in 2016 economic growth rates within the frameworks of that scenario amount to $0.2 \%$ against the previous year with their subsequent growth to $2.2 \%$ provided that Urals oil prices are at $\$ 40$ a barrel in 2016-2019.

1 This paper was originally published in Online Monitoring of Russia's Economic Outlook No.9(27).

2 Order No.122-rp of 16 May 2016 on Approval of the Statutes on the Working Group in the Line: "Priorities of Structural Reforms and Stable Economic Growth" of the Economic Council under the RF President and the Composition Thereof.

3 http://economy.gov.ru/minec/about/structure/depMacro/20160506 
Under the conservative scenario, development of the Russian economy takes place in less favorable conditions, namely: the average annual oil price will fall to $\$ 25$ a barrel and remain at that level until 2019. It is to be noted that dynamics of the RF's main macroeconomic indicators is explicitly negative. So, in 2016 a GDP drop will amount to $2.1 \%$ on the previous year with a subsequent stabilization attained in 2017 and positive values of $0.7-1.6 \%$, in 2018-2019.

"The target scenario is aimed at achievement of target indicators of the socioeconomic development and solution of objectives of strategic planning" ${ }^{11}$ and suggests attainment of a macroeconomic equilibrium and the Russian economy's embarking on the trajectory of sustained GDP growth at the level which is not lower that the average global one (that is, attainment by 2019 of GDP growth rates of $4.5 \%$ on the previous year). The MED expects that within the frameworks of the target scenario the development of the economy takes place under trade conditions which are similar to those of the baseline one, but based on a new investment model of development with restrained growth in social obligations of the government and business in the first few years of the period under review.

So, there is only one scenario proposed by the MED that suggests a possibility of desirable growth rates of $4 \%$ to be achieved by 2019. Moreover, it is believed that with the above stated prerequisites and prevailing external conditions materialization of the baseline scenario requires serious changes in internal conditions of economic development.

The above is underpinned by the results of decomposition of forecast values of GDP growth rates on the basis of the methods developed by the Gaidar Institute; the above methods are based on the procedure - applied in OECD countries and adapted to the specifics of the Russian economy which is highly dependent on conditions of trade - for breaking down GDP growth rates into components ${ }^{2}$. Decomposition was carried out on the basis of the main parameters of the scenario forecast of the socioeconomic development of Russia in 2016-2019.

Dynamics of Russia's GDP actual growth rates, as well as structural, foreign trade and cyclical (the aggregate of components of business-cycles and random shocks) components in the 1999-2015 period received on the basis of the results of decomposition are shown in Fig. 1.

According to our calculations, the structural component of GDP growth has been slowing down since 2005 and amounts to $1.5 \%$ in 2015. The above trend can be explained by negative dynamics of fundamental factors of economic growth: a decrease in the number of gainfully employed population (that is, labor factor) due to unfavorable demographic trends amid slowdown of growth rates of capital assets (serving as a proxy variable for the capital factor). In addition to the above, reduction of the structural component of growth can be justified by a decrease in the aggregate factor pro-

1 http://economy.gov.ru/minec/about/structure/depMacro/20160506

2 For more detail regarding the methods in question, see S. Sinelnikov-Murylev, S. Drobyshevsky and M. Kazakova. Decomposition of Russia's GDP Growth Rates in 19992014 // Economic Policy. 2014. No.5. pp. 7-37, as well as the treatise: Decomposition of Russia's GDP Growth Rates / S. Sinelnikov-Murylev [and other]. -M. : the Gaidar Institute's Publishing House, 2015. - p. 128. : Scientific Works / Gaidar Institute for Economic Policy; No.167R). 


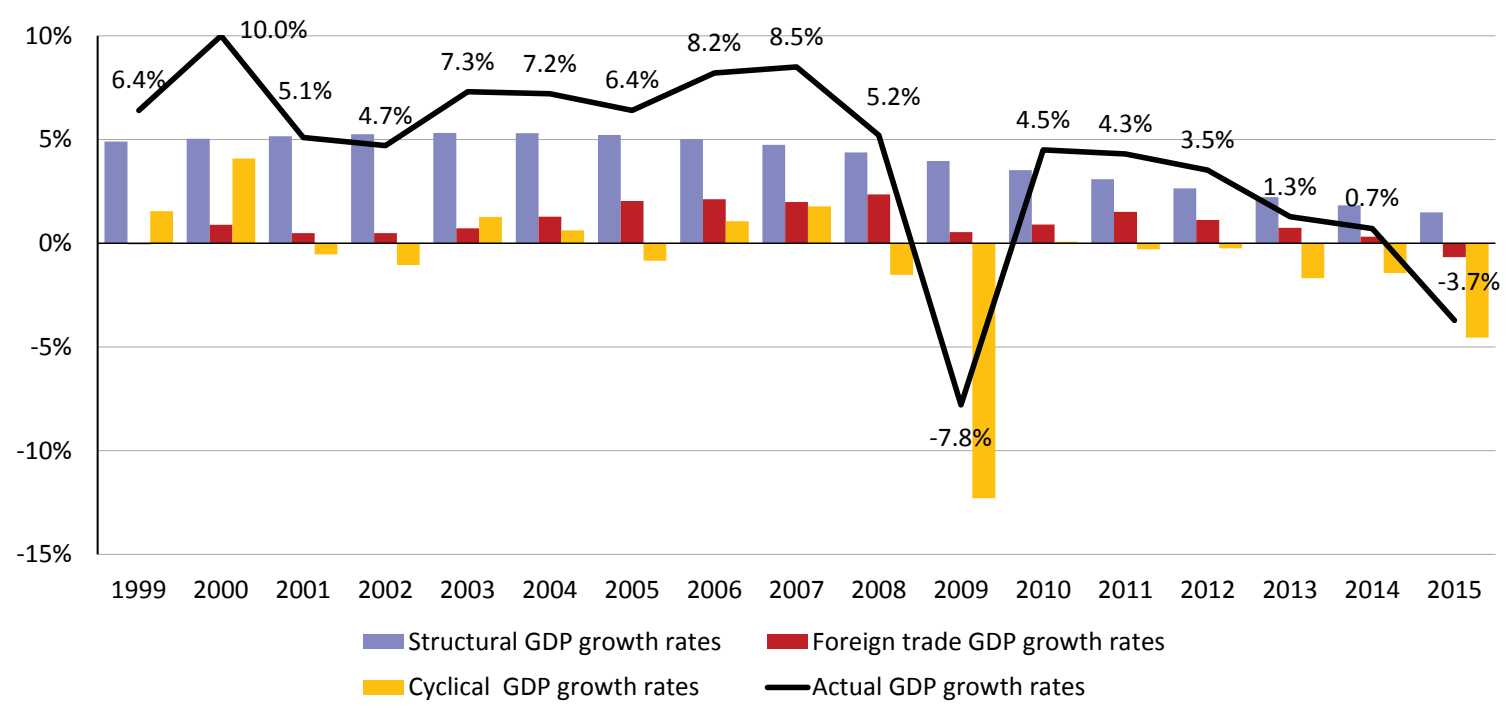

Sources: Rosstat, MED, IMF and our calculations.

Fig. 1. Actual growth rates of GDP and its components, \% on the previous year, 1999-2015

ductivity which includes a contribution of other factors of growth apart from labor and capital.

As regards the cyclical component of Russia's GDP growth rates, as seen from Fig. 1 in 2013-2015 it was in a negative zone (-4.6\% in 2015), which fact can sooner be explained by a shock representing a combination of negative consequences caused by economic sanctions and counter-sanctions, growing uncertainties and risks in the economy amid high volatility of the rouble exchange rate, higher inflation rate and lack of foreign borrowed funds.

Reviewing decomposition of forecast growth rates of GDP in 2016-2019, as regards the baseline and target scenarios it is to be noted that the levels of global oil prices in 2016-2019 envisaged in all the forecast scenarios are below the average multiyear levels ( $\$ 80-85$ a barrel) which fact explains negative values of the foreign trade component of GDP growth rates in the above years (Fig. 2-3).

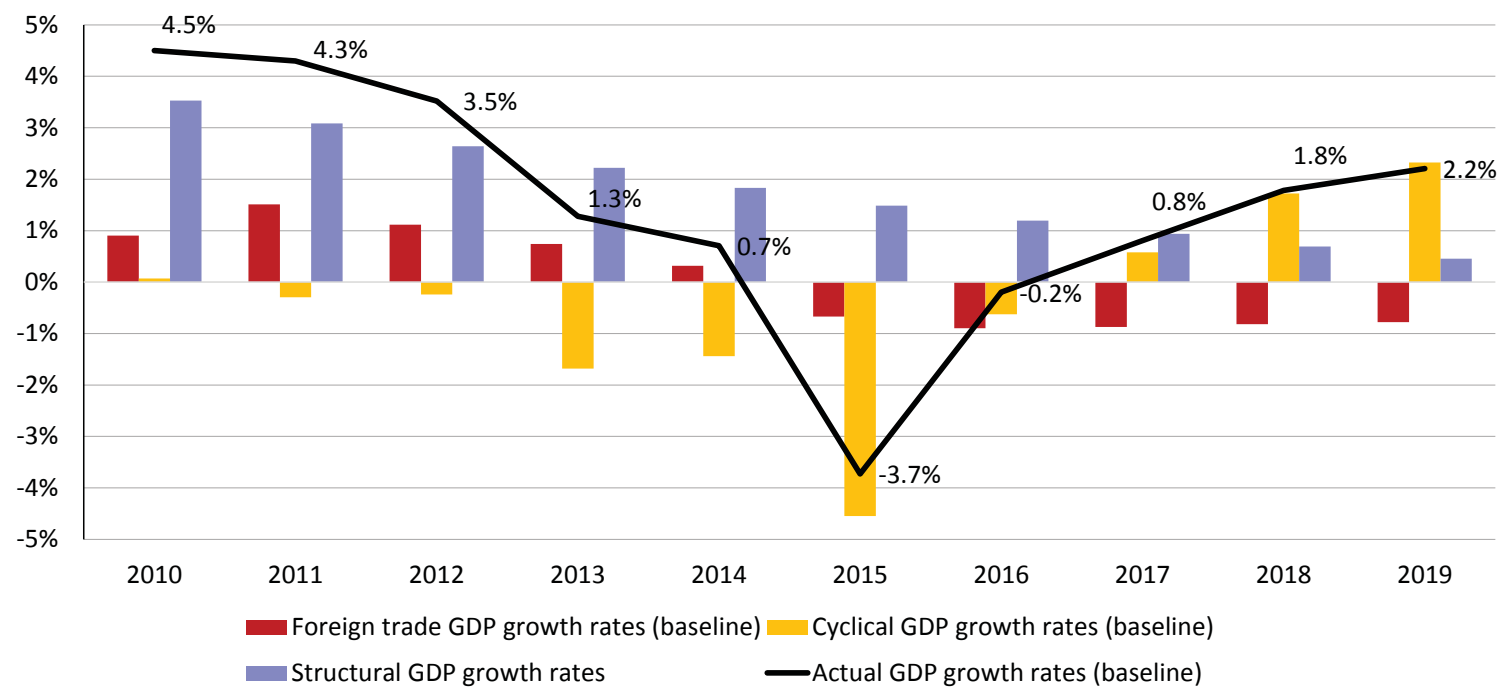

Sources: Rosstat, MED, IMF and out calculations.

Fig. 2. GDP growth rates and its components, \% on the previous year, 2010-2019 (baseline forecast scenario) 


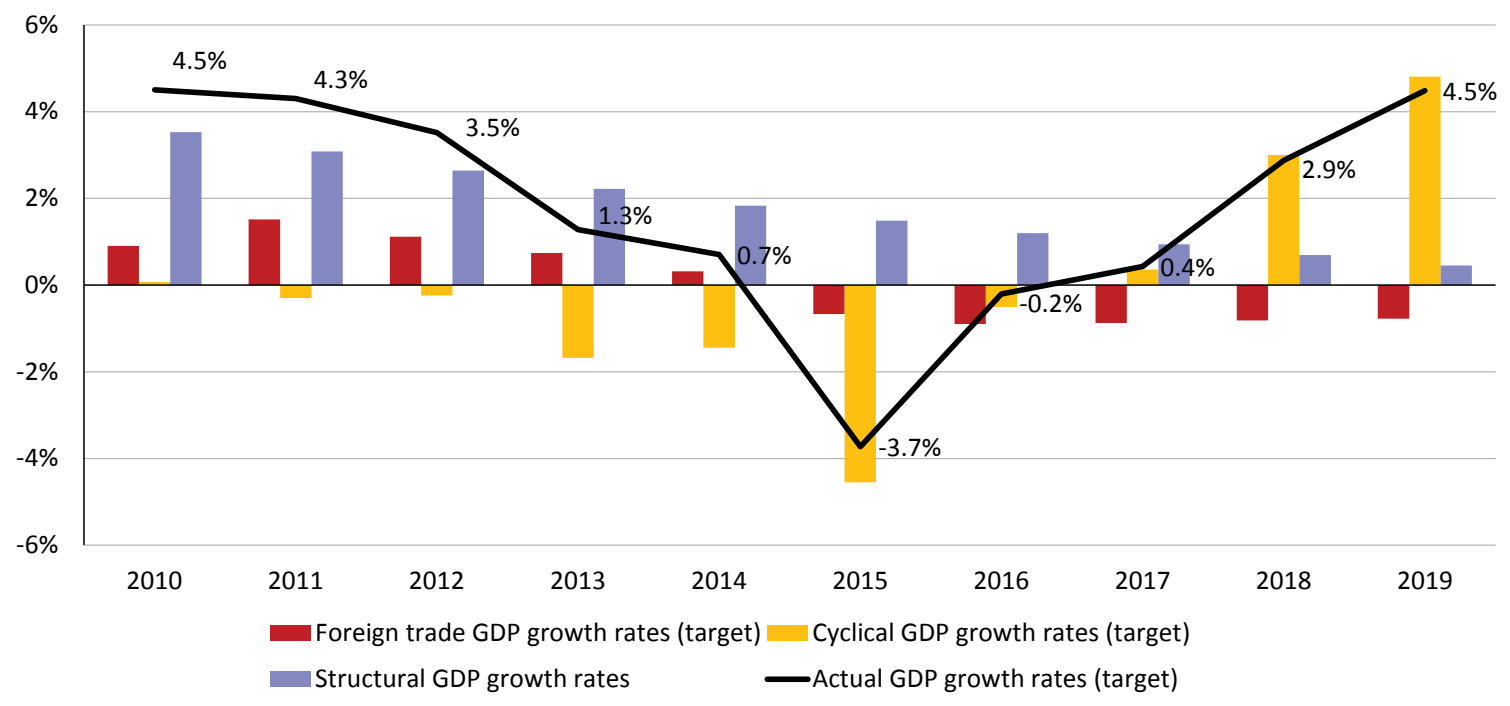

Sources: Rosstat, MED, IMF and our calculations.

Fig. 3. Growth rates of GDP and its components, \% on the previous year, 2010-2019 (target forecast scenario)

Decomposition of growth rates in 2016-2019 shows that in a situation where oil prices remain below average multiyear ones, while a structural component is falling due to a lack of growth both in fundamental factors of economic development and the aggregate factor productivity materialization of forecast growth rates of the Russian GDP is feasible only at the expense of the cyclical component. For example, within the frameworks of the baseline and conservative scenarios the cyclical component is expected to grow to $2.3 \%$ by 2019 , while in the target scenario, to $4.8 \%$. Such growth in the cyclical component can be the result either of a sudden acceleration of cyclical GDP growth after the negative shock which was observed in 2015 has gone, or under assumption that the economy remains in a low phase of the business cycle and there is a substantial positive shock whose nature is not quite clear.

Output gap (deviation of GDP from the natural output volume) assessed on the basis of decomposition is shown in Fig.4. In 2015, output gap fell into the negative zone under conditions of materialization of the MED's baseline and target scenarios and remains there for the period of three years until 2018. In case of materialization of the conservative scenario, the negative output gap remains negative in the range of $3-4 \%$ throughout the period under review.

In view of the obtained results, there is a question which factors could contribute to materialization of the MED's parameters of the target forecast scenario. Firstly, as shown above the Russian economy cannot rely on favorable trade conditions as throughout the entire forecast period quite a moderate level of oil prices - much lower than the average multiyear one - is expected. Secondly, there are no prerequisites for growth in the cyclical component, either.

So, growth in the structural component is still the only way of achieving the desirable economic growth rates. In other words, the prerequisite for materialization of the most optimistic scenario, namely, achievement by 2019 of sustained GDP growth rates at the level of average global ones (about $4 \%$ on the previous year) is a substantial speed-up of growth in fundamental factors 


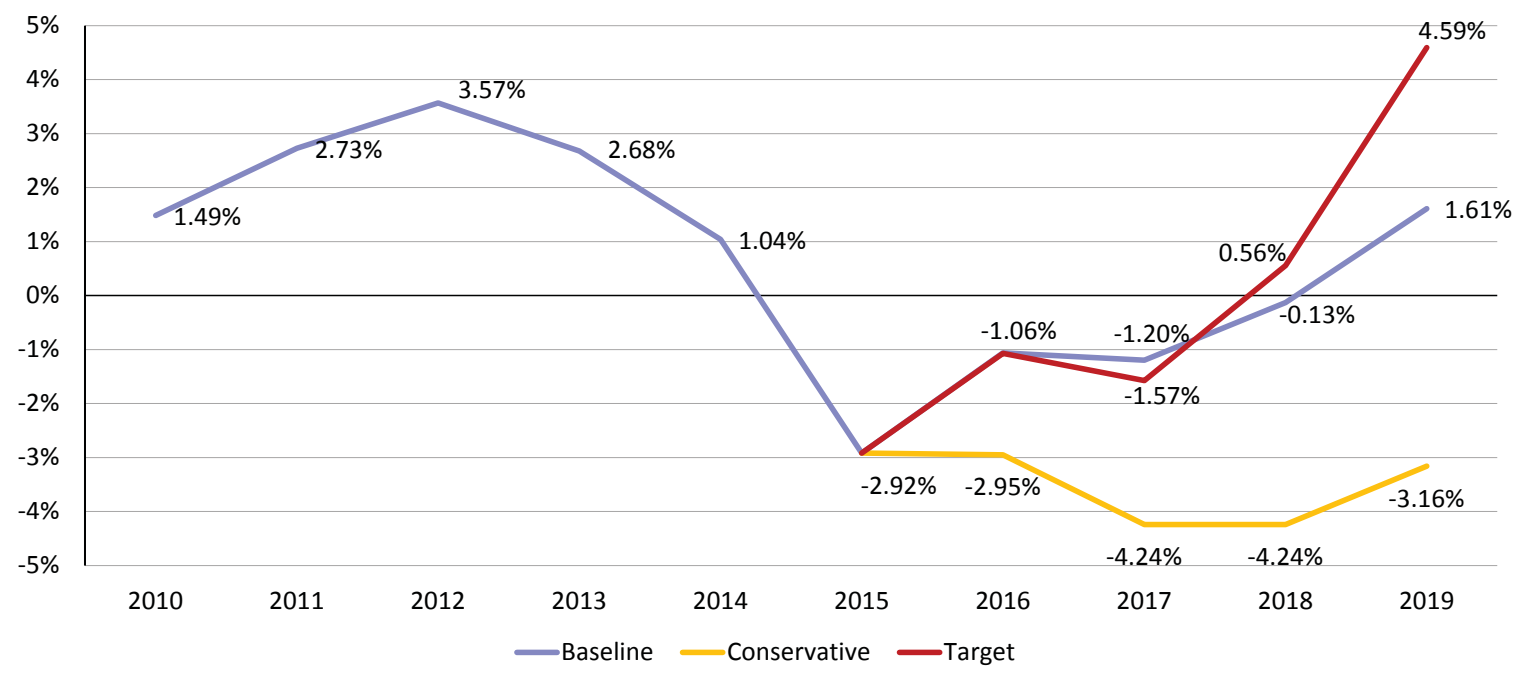

Source: Our calculations.

Fig. 4. Output gap in the Russian economy (\%), 2010-2019 (forecast on three scenarios)

ensuring formation of GDP. According to our calculations, with the aggregate factor productivity remaining at the current level (this prerequisite is quite a realistic one amid the existing sanctions and lack of influx of foreign capital as described by the MED) to achieve that goal further attraction to the economy of labor resources of about $4.5 \mathrm{~m}$ people and $\mathrm{Rb} 40$ trillion worth of additional capital investments is required in the 2016-2018 period. 